\title{
Recurrent Macular Corneal Dystrophy Following Penetrating Keratoplasty
}

\author{
Y. A. AKOVA, C. M. KIRKNESS, A. C. E. McCARTNEY, L. A. FICKER, \\ N. S. C. RICE and A. D. McG. STEELE \\ London
}

\begin{abstract}
Summary
The recurrence of macular corneal dystrophy within a corneal graft has been described in a number of case reports. In this study, we reviewed 41 transplants in 31 eyes of 16 patients undergoing keratoplasty for macular corneal dystrophy confirmed by histopathological examination. The follow-up time ranged between 25 and 408 months from initial diagnosis. Six eyes of four patients had repeat keratoplasty because of clinical recurrence and visual impairment. Pathological confirmation was available in five of the six eyes. Peripheral clinical recurrence was observed in two more eyes. The size of the graft used was inversely related to the recurrence.
\end{abstract}

Macular corneal dystrophy (MCD) is a rare recessive disorder characterised clinically by the presence of bilateral opacities resulting from intra- and extra-cellular deposits within the corneal stroma. ${ }^{1-3}$ This dystrophy was first described by Groenouw 100 years ago. ${ }^{4}$ In patients with the disease, the opacities tend to be small, irregular and superficial during the first decade of life. The lesions then gradually increase to an advanced stage in which the entire thickness of the cornea is almost invariably involved by the fourth decade and stromal opacification reduces vision sufficiently to warrant penetrating keratoplasty ${ }^{1,3}(\mathrm{PK})$.

Histochemically, MCD consists of the accumulation of glycosaminoglycans within stromal keratocytes and the surrounding stroma, in Bowman's layer, Descemet's membrane and the endothelium. ${ }^{5-8}$ Organ culture studies have recently indicated the presence of a defect in the synthesis of keratan sulphate proteoglycan. The replacement of keratan sulphate by a glycoprotein with similar immunological characteristics and with slightly smaller molecular weights has been proposed as the mechanism of the disease..$^{3,9,10}$ Corneal thinning confirmed by pachymetry has recently been demonstrated but the reasons for this are obscure. ${ }^{11} \mathrm{MCD}$ may show heterogeneity in structure having at least three sub-groups that can be identified by immunohistochemical methods. ${ }^{12,13}$ No correlations, however, could be found between clinical features, staining characteristics, ultrastructural morphology and immunoreactivity to keratan sulphate antibodies.

Keratoplasty is the only means of visual rehabilitation in the disease and after transplantation the corneal graft remains clear for many years. ${ }^{14}$ The recurrence of dystrophic changes within the donor tissue is a recognised complication..$^{815-19}$ Initial lesions are usually seen in the peripheral donor stroma, involving both superficial and deep stromal

From the Corneal Clinic, Moorfields Eye Hospital, City Road, and Dept of Pathology, Institute of Ophthalmology, Cayton Street, London EC1.

Correspondence to: $\mathrm{Mr}$ C. M. Kirkness, FCOphth, Pocklington Transplantation Unit, Institute of Ophthalmology, Moorfields Eye Hospital, City Road, London EC1V 2PD. 


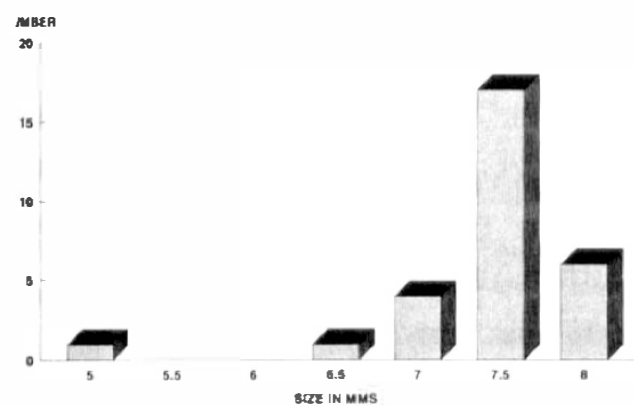

Fig. 1. The size of each penetrating graft performed in this series.

layers. Later the graft itself may be compromised by lesions resembling the primary dystrophy.

In the present study, the long-term prognosis of 41 keratoplasties (39 PKs and 2 lamellar grafts $[\mathrm{LK}])$ performed on 16 patients with MCD is reported. Particular reference is made to the reason for the failure of the original graft and the need for repeat keratoplasty.

\section{Patients and Methods}

The files of all patients with MCD who had originally undergone keratoplasties in Moorfields Eye Hospital between 1964-1988 were reviewed to identify recurrence of the disease in the grafts. Factors analysed included age of onset, family history, age at keratoplasty, type of surgery and graft size, clinical recurrence, interval between $\mathrm{PK}$ and recurrence, repeat PK for recurrence, histopathology, other reason for graft failure and graft survival and follow-up.

Bilateral grafts were performed in 15

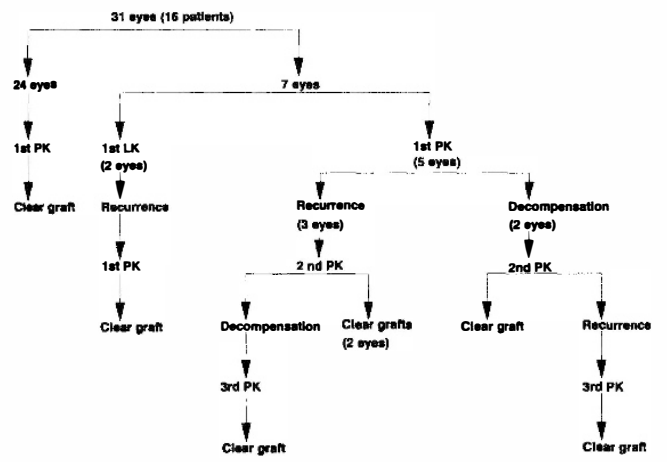

Fig. 2. Schematic representation of the outcome of all the grafts in this series. patients and a unilateral graft was done in one case where amblyopia in the other eye precluded useful recovery of visual function. There were eight men and eight women in the study. A total of two lamellar and 39 penetrating keratoplasties were performed in these 31 eyes.

Statistical analysis of recurrence in relation to graft size was by means of the Kruskal Wallis variant of Wilcoxon rank sum test and the survival curve was produced by the standard Kaplan and Meier method. For the purposes of this paper, recurrence is defined as opacity, developing within the graft, dense enough to reduce substantially the patient's visual acuity and warrant repeat keratoplasty.

\section{Results}

The mean $( \pm S E M)$ age when decreased vision was first noticed by the patient was 28 $( \pm 3)$ years $)$. Nine $(56 \%)$ patients reported at least one other individual in their families known to be affected. Parental consanguinity was noted in three patients (18\%). The mean follow up period was $149( \pm 29)$ months. The mean age at the time of first keratoplasty was $41( \pm 4)$ years. Graft sizes ranged from 5-8 mm (Figure 1).

Figure 2 shows the course of the disease and the operations performed in all the patients. Of the 31 eyes of 16 patients studied, 24 $(77.4 \%)$ had only a single PK and this has remained clear. One patient had bilateral lamellar grafts initially. Recurrence of the dystrophy was seen at nine and 15 years respectively. Both eyes underwent sub-

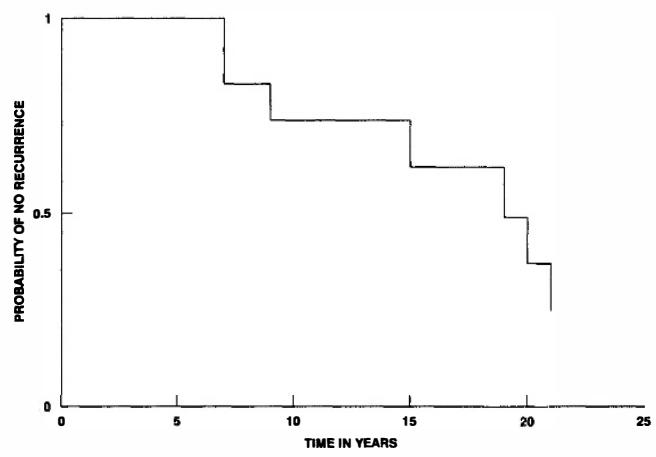

Fig. 3. The probability of there being no recurrence of macular dystrophy within the donor button. Only cases severe enough to indicate repeat keratoplasty are included. Early clinical presumptions of recurrence are excluded. 


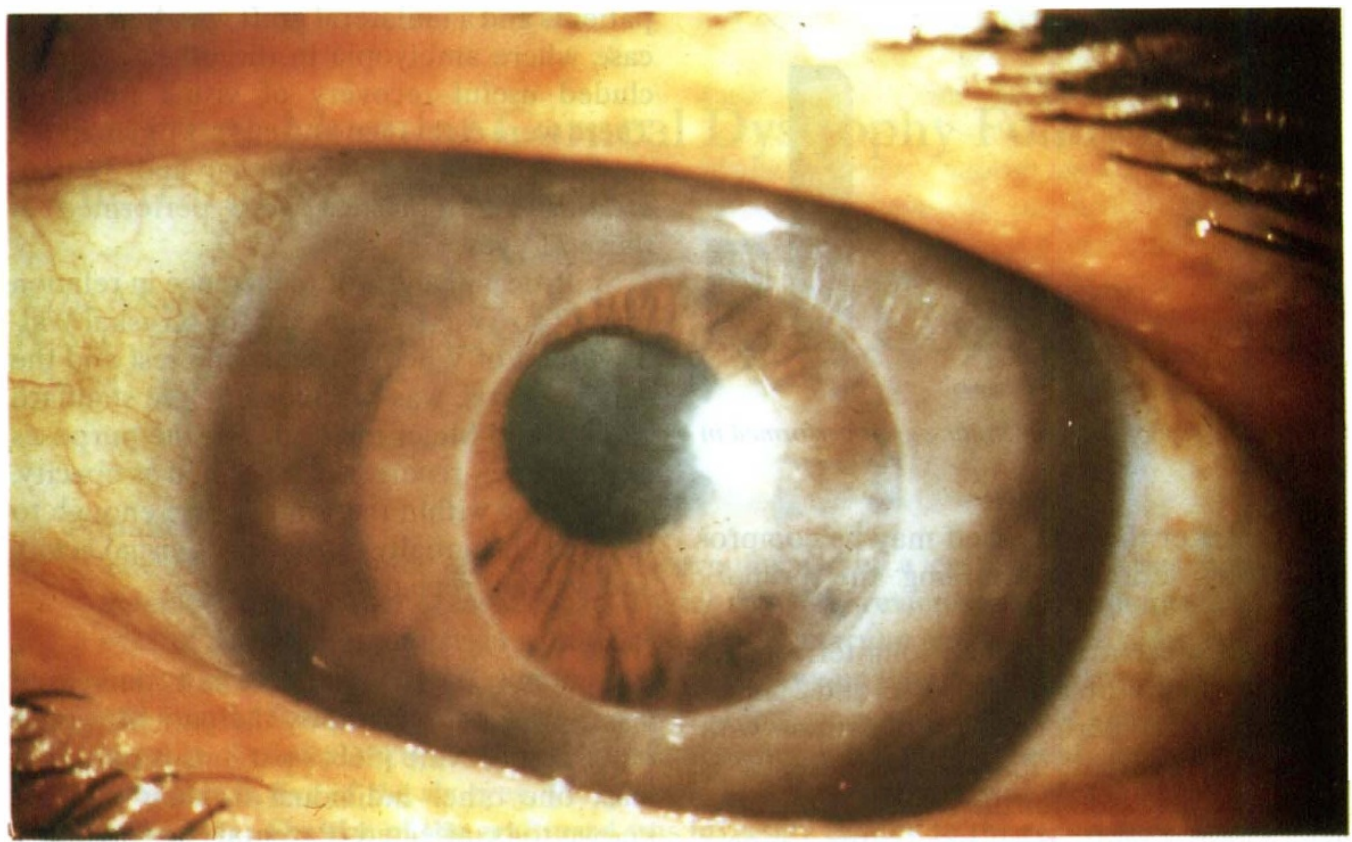

Fig. 4. There is a marked recurrence of MCD in one quadrant of this small graft. Repeat keratoplasty was necessary within 3 years.

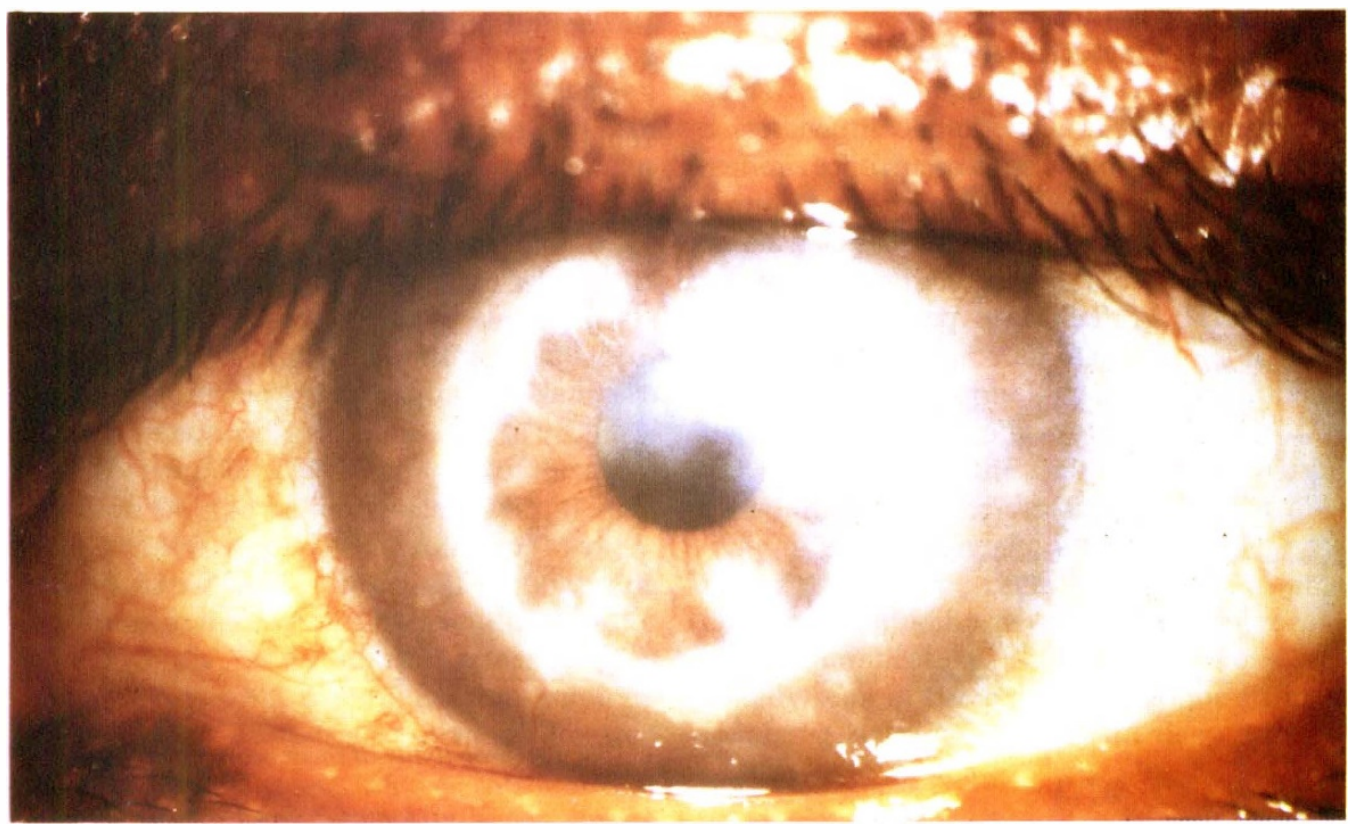

Fig. 5. Dense areas of recurrence are seen around the suture tracks in this graft but the central cornea is also involved and regraft was performed because of reduced vision. 


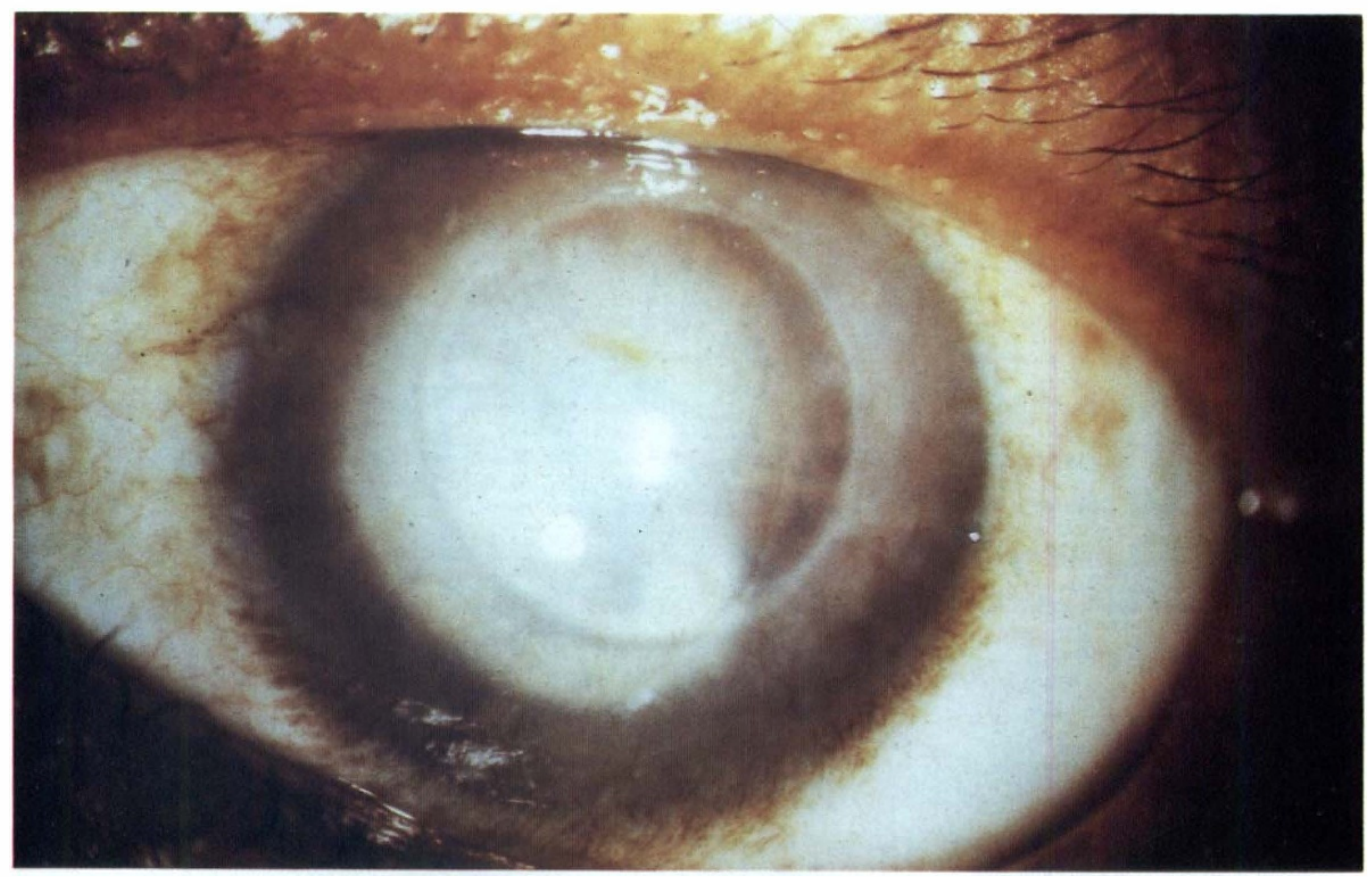

Fig. 6. The contralateral eye to that shown in Fig. 5. The recurrence is much denser centrally in this graft. Although it resembles lipid keratopathy, there was no evidence of lipid on histology.

sequent PK and these grafts are clear nine and three years later.

The probability curve of no recurrence of disease is shown in Figure 3. All the keratoplasties in this series are included and the graph suggests that there is a $50 \%$ probability of recurrence of MCD in a graft by about 19 years. MCD recurred in three first-time grafts (PKs). Repeat keratoplasty was performed in all three. One developed a rejection, failed and has subsequently undergone a further PK which is clear at this review, three years later. The other two remain clear, four and five years later.

Two first-time grafts suffered rejection episodes and failed. One has maintained a clear graft following repeat keratoplasty for five years, the other developed recurrence and was regrafted and this has remained clear three years later.

In all, six eyes of four patients were regrafted following clinical recurrence severe enough to reduce vision substantially (Figures $4,5,6)$. Histopathological confirmation was available in five of these keratoplasties (Figures 7, 8).
The mean interval between initial PK and recurrence was $182( \pm 29)$ months. The mean follow-up period in cases with recurrent MCD was $264( \pm 53)$ whereas in those with clear grafts this was $111( \pm 27)$ months. This difference is significant, $\mathrm{p}<0.05$. When the size of the graft was compared, those with recurrence (mean $6.37( \pm 0.47) \mathrm{mm})$ were significantly smaller than those remaining clear (mean $7.52( \pm 0.06) \mathrm{mm}) \mathrm{p}<0.01$.

\section{Discussion}

In patients with MCD and technically successful grafts, the donor tissue remains transparent in the absence of rejection for many years. ${ }^{18}$ Recurrence of the dystrophy has been reported as early as three years after transplantation. $^{15,16}$ Histologically documented recurrences are most prominent in the peripheral cornea and this may indicate that the disease is caused by gradual invasion of the donor tissue by adjacent fibroblasts or keratocytes from the host cornea. ${ }^{3,18,20}$

The recurrence of MCD was first noted by Klintworth and Vogel $^{8}$ who reported mucopolysaccharide deposits in donor tissues two- 


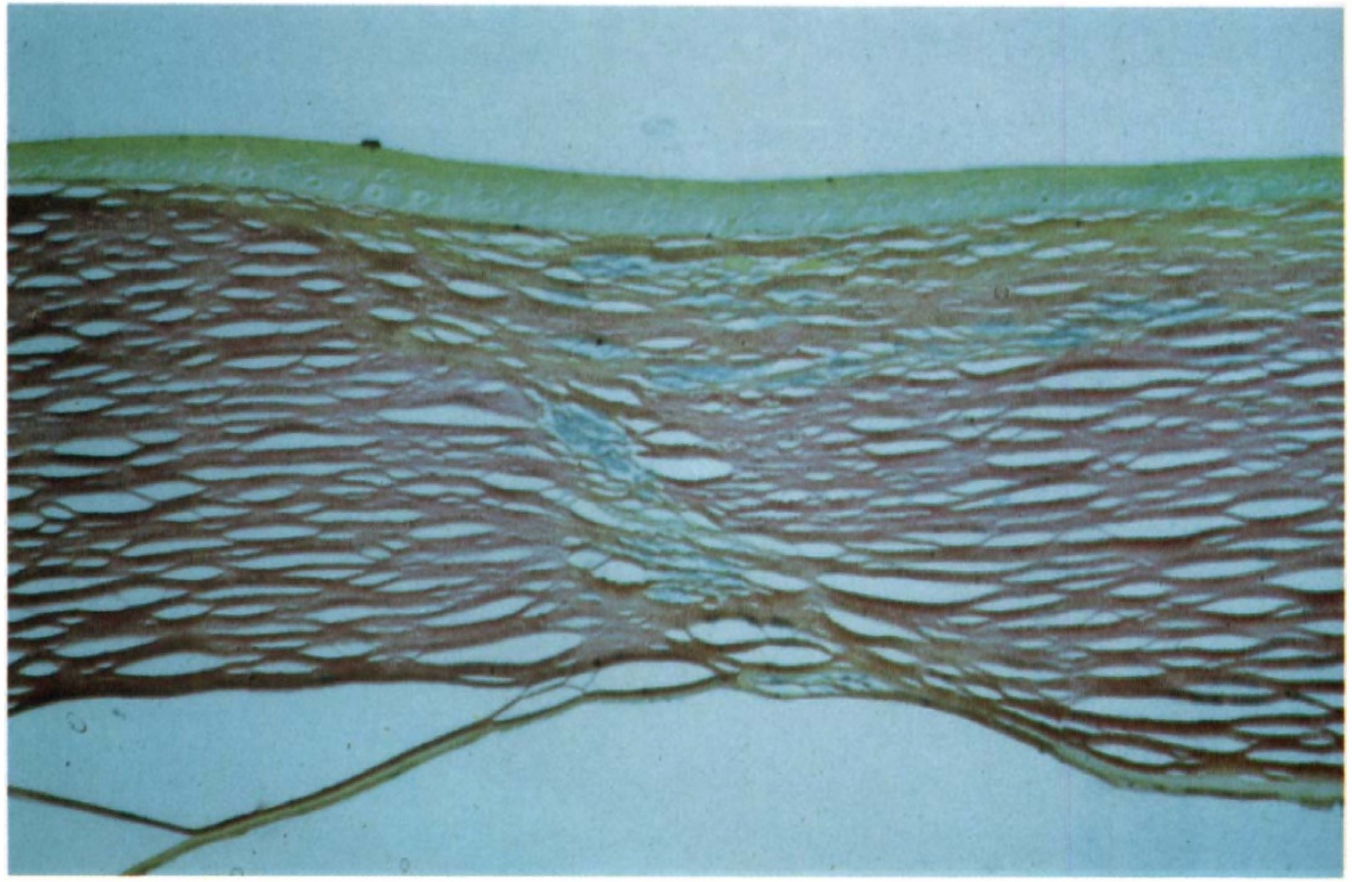

Fig. 7. Site of interface between graft and host showing heavy deposits of glycosaminoglycans and no evidence of passive seepage into the donor material. Hales colloidal iron, original magnification $\times 16$.

five years after PK. Soon afterwards Morgan ${ }^{15}$ showed recurrence of disease in the donor button three years after original transplantation. In 1967, Lorenzetti and Kaufman ${ }^{16}$ reported a patient with MCD whose grafts became opaque 20 and 27 months after bilateral corneal grafting and cataract extraction. They found recurrent disease in the corneal stroma and the endothelium of the graft and suggested that acid mucopolysaccharides may have diffused into the donor tissue causing recurrence. More recently Robin et al. ${ }^{17}$ described another patient who had developed recurrent disease 11 years after lamellar keratoplasty. Following penetrating keratoplasty the excised button had the characteristic findings of MCD in the donor. Klintworth et al. ${ }^{18}$ published two further cases requiring PK 18 and 19 years following PK. Histochemical and electron microscopic features of MCD were demonstrated in the grafts. They communicated that of 198 known patients with MCD in the USA only five $(2.5 \%)$ had visual impairment severe enough to warrant repeat keratoplasty. Since most of these 198 grafts are not under continuous review by the authors it seems probable that this may represent considerable under reporting of the true incidence. Font et al. ${ }^{19}$ have also reported one case of recurrence in a graft 30 years following PK in which the indication for repeat keratoplasty was endothelial failure. In our group of patients with long and regular follow-up within the same institution, clinical recurrence was $19.3 \%$ of which $83.3 \%$ were pathologically confirmed. If peripheral lesions are included the total recurrence rate is $25.8 \%$. Reported recurrence times are between 20 months and 30 years. ${ }^{8,15-19}$ In the present study the mean recurrence time was 182 months but the actuarial curve indicates that there is a $50 \%$ chance of recurrence within a graft at 18 years. Only a very few patients have been followed for longer than 20 years. It is worth noting however that as keratoplasty was developing 20 years ago smaller grafts were much more common than nowadays. Our results indicate an inverse relationship between size of graft and likelihood of recurrence and it may be that with increasing donor size there will be a consequent increase in graft survival. We have no 


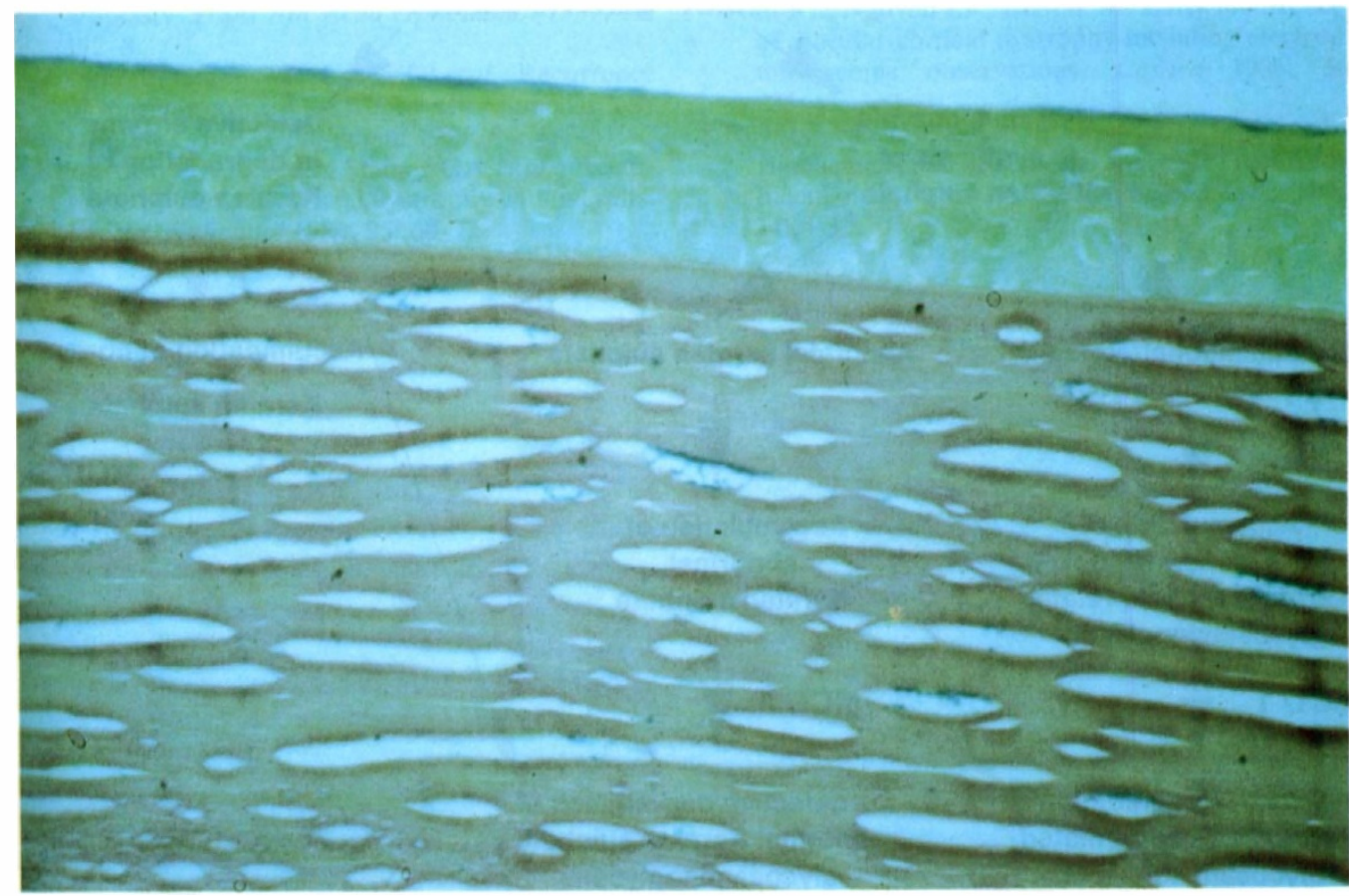

Fig. 8. Central part of grafted cornea showing recurrent macular dystrophic deposits lying between collagen lamellae, quite unrelated to surgical interface or to suture tracks. Hales colloidal iron, original magnification $\times 40$.

data, nor could we find any published work, to indicate that different methods of corneal donor storage would influence the rate of recurrence.

Lamellar keratoplasty has not been considered preferable for the treatment of MCD since the host corneal stroma is not removed completely. ${ }^{14,18}$ Klintworth et al. ${ }^{18}$ proposed that diseased keratocytes migrating from the host into the donor tissue were responsible for the recurrence thus explaining the tendency of the lesions to be more pronounced in the peripheral grafted cornea. The pattern of the interface recurrence in our two grafts from the one patient who had lamellar grafts supports this contention.

Newsome et al. ${ }^{20}$ indicated that a considerable amount of abnormal glycoprotein was synthesised by the host keratocytes. This pooled and was concentrated near the donor Descemet's membrane and eventually diffused into the stroma. Using HLA typing methods they were also able to show donor keratocytes were still present in the grafts 25 years after transplantation. The inverse relationship found between graft size and the frequency of recurrence reported here is consistent with these observations and may indicate that smaller grafts are more readily invaded by abnormal glycoproteins and or stromal cells. Whether the loss of clarity results from depletion of donor keratocytes and the ingrowth of abnormal host keratocytes or whether the remaining donor cells are overwhelmed by the abnormal metabolite is not yet clear. Furthermore, it is not clear whether the accumulation is due to an imbalance of secretion alone or whether catabolism and removal of the metabolite is also impaired. It is possible that either defective synthesis or degradation or a combination of both is present in these patients and it is likely that MCD is a heterogenous group of disorders rather than a single entity. ${ }^{12,13}$ This may explain the selective rarity of recurrence in this condition and the variation between different populations and the patterns of disease. We did not observe endothelial cell accumulation of abnormal metabolite in any grafted cornea whereas it is a common phenomenon in the original specimens.

Patients with MCD undergoing kerato- 


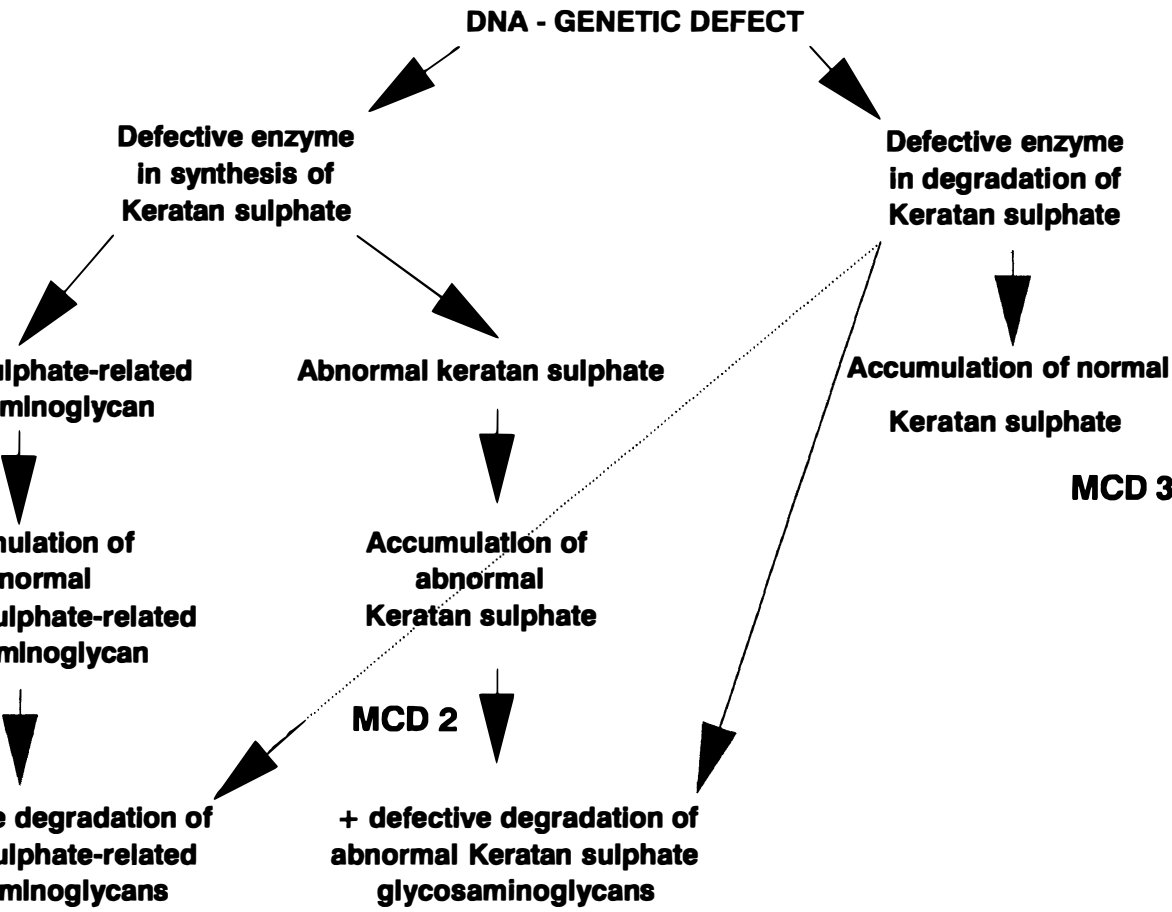

MCD 4

MCD 5

Fig. 9. The heterogeneity of macular corneal dystrophy with five possible pathways resulting in MCD. (After Klintworth-personal communication).

plasty should be followed long term. They may require repeat keratoplasty when their vision is obscured by recurrence of MCD but larger sized grafts may delay or prevent this.

\section{References}

${ }^{1}$ Waring GO III, Rodrigues MM, Laibson PR: Corneal dystrophies of the epithelium, Bowman's layer and stroma. Surv Ophthalmol 1978, 23: 71-122.

${ }^{2}$ Waring GO III, Rodrigues MM, Laibson PR: Corneal dystrophies. In Leibowitz ed. Corneal Disorders: clinical diagnosis and management. Philadelphia: WB Saunders 1984, 57-99.

${ }^{3}$ Klintworth GK: Macular corneal dystrophy. A localized disorder of mucopolysaccharide metabolism? In (Daentl DL ed.) Clinical, structural and biochemical advances in hereditary eye disorders. New York: Alan R Liss Inc, 1982, 64-101.

${ }^{4}$ Groenouw A: Knötchenfömige Hornhauttrubungen. Arch Augenheilkd 1890, 21: 281-9.

${ }^{5}$ Jones ST and Zimmerman LE: Histopathologic differentiation of granular, macular and lattice dystrophies of the cornea. Am J Ophthalmol 1961, 51: 394-410.

${ }^{6}$ Garner A: Histochemistry of corneal macular dystrophy. Invest Ophthalmol Vis Sci 1969, 8: 473-83.
${ }^{7}$ Teng CC: Macular dystrophy of the cornea. A histochemical and electron microscope study. Am J Ophthalmol 1966, 62: 436-54.

${ }^{8}$ Klintworth G and Vogel FS: Macular corneal dystrophy: an inherited mucopolysaccharide storage disease of the corneal fibroblast. Am J Pathol 1964, 50: 565-86.

${ }^{9}$ Klintworth GK: Current concept of macular cornea dystrophy. Birth Defects 1982, 18: 463-77.

${ }^{10}$ Rodrigues MM and Krachmer J: Recent advances in corneal stromal dystrophies. Cornea 1988, 7: 19-29.

${ }^{11}$ Donnenfield ED, Cohen EJ, Ingrahan $\mathrm{HJ}$ et al.: Corneal thinning in macular corneal dystrophy. Am J Ophthalmol 1986, 106: 112-3

${ }^{12}$ Yang CJ, Sundar RN, Thonar EJMA et al.: Immunohistochemical evidence of heterogeneity in macular corneal dystrophy. Am J Ophthalmol 1988, 106: 65-71.

${ }^{13}$ Edward DP, Yue BYJT, Sugar J et al. : Heterogeneity in macular corneal dystrophy. Arch Ophthalmol 1988, 106: 1579-83.

${ }^{14}$ Klintworth GK: Research into the pathogenesis of macular corneal dystrophy. Trans Ophthalmol Soc UK 1980, 100: 186-94.

${ }^{15}$ Morgan G: Macular dystrophy of the cornea. Br J Ophthalmol 1966, 50: 57-67.

${ }^{16}$ Lorenzetti DWC and Kaufman HE: Macular and lattice dystrophies and their recurrence after Ker- 
atoplasty. Trans Am Acad Ophthalmol 1967, 71: 112-8.

${ }^{17}$ Robin AL, Green WR, Lapsa TP et al.: Recurrence of macular corneal dystrophy after lamellar keratoplasty. Am J Ophthalmol 1977, 84: 457-61.

${ }^{18}$ Klintworth GK, Reed J, Stainer GA et al.: Recurrence of macular corneal dystrophy within grafts. Am J Ophthalmol 1983, 95: 60-72.
${ }^{19}$ Font RL, Nguyen LK, Boniuk M: Early recurrence of macular corneal dystrophy including electron microscopic observations. Cornea 1986, 5: 235-43.

${ }^{20}$ Newsome DA, Hassell JR, Rodrigues MM et al.: Biochemical and histological analysis of recurrent macular dystrophy. Arch Ophthalmol 1982, 100: 1125-31. 